\title{
From Functional Areas towards Metropolitan Structure: Public Space in Sustainable Development Context
}

\author{
SOUREK Michal ${ }^{1, \text { a * }}$ \\ ${ }^{1}$ Czech Technical University in Prague, Faculty of Civil Engineering, Department of Architecture, \\ CZ 16629 Prague 6, Czech Republic \\ asourek@msgroup.cz
}

\begin{abstract}
Keywords: Public space, communication, social-cultural and material values, city - polis, built environment, brownfield, deteriorated locality, urban fallow, modern era built heritage, sustainable development, sustainable life, architecture, civil engineering, urban planning
\end{abstract}

\begin{abstract}
If sustainable life on Earth is the goal (today), the Mankind cannot head towards it living in cities that are not sustainable. Localities that have lost the ability, unduly frequent in our cities, call the nature and causes of the phenomenon to be revisited. Once perceived in a city context, brownfields appear as places where the city failed: the communication, both material and socialcultural values' exchange - that is the fundamental principle of a city - reduced and finally stopped between the locality, its surroundings and the polis. Identified as a platform for the communication, public space creates the basic framework of a city - the metropolitan structure. Vital public space claims to be the base of sustainable development of a city thus: the paper verifies the hypothesis and provides essential description of functions and types of public space. Principles and methods of its formation are demonstrated on examples in a nutshell. Eventually, the paper contributes both to the positive and to the normative theory of urban public space. Richly documented both in literature and the author's own work, commonly accessible reality of the built environment is the platform of explorative research plan of the paper. New, revising conclusions do not result from new findings on the situation, but from new perspectives on familiar issues. The same platform allows easy verification of hypotheses and new explanations.
\end{abstract}

\section{Localities that Have Failed to Be Sustainable: State of Affairs and Nature of the Problem}

Dilapidated, abandoned and derelict buildings and sites are highly visible phenomenon of European cities and landscapes of the late twentieth and early twenty-first century. Named industrial heritage, urban fallows, deteriorated neighborhoods, brownfields or socially excluded localities, they represent values on the one hand and loss of them on the other. After all, it is about the same in any case: lands and buildings that have lost the original function and have not found a new one, not used, abandoned and shabby, often a source or an epicenter of social-pathological effects, safety and hygiene hazards. Harming both people, society and environment, they are places where the city failed to work. They are dead localities where the processes that represent social-cultural basis of a city have ceased: the communication - an exchange of values between the site, its surroundings and the community has declined until it stopped. At the beginning, the limitation interferes in culturalcivilizational area as a rule: knowledge transfer and development fall among the first typically, the deficit affects transfer and sharing of other social-cultural values, too; the decline of economical exchange follows. In material realm, the flow of capital, raw materials, media and labor force in one direction and produced goods and earnings in the other go down. Loss of control over wear and tear and dilapidation of the locality together with negative social impact are the consequence. Finally, the people's motion between the site and the city disappears - perhaps with an exception of pathological phenomena such as vandalism, larceny or criminals' and socially excluded individuals' and groups' refuge. Health and safety risks have been already mentioned as concomitants of the situation: they amplify the exclusion of the locality and strengthen the communication barriers. 
It is worth noting that all the characteristics mentioned fit no less tightly to an industrial brownfield than to a deprived neighborhood. At the same time, any of the characteristics is the inverse to an essential principle both the idea and running of a city-of polis - are based on

\section{Hypothesis: Public Space is the Basis of Sustainable Development of a City}

On top of the two common aspects of all the processes of built environment localities decline or non-sustainable development - universality regarding the original use and denial of the basic principles of polis - there is a third one in addition: all the processes take place in a public space. Public space is a platform for communication in an urban, or broadly in a built environment context, whether it is the physical public space of a city [5], or the public space of social, cultural and civilizational interactions [4], amongst them the economical, administrative, political, and also intellectual in the broadest sense are to be emphasized. Starting maybe from general application of the press, at latest from development of electronic communication technologies (electric telegraph in 1836 and 1839) and later digital media networks, social and cultural-civilizational interactions partially leave the physical platform; but even in the future they will probably not leave it completely. All kinds of communication between different parts of built environment - and among the people, the community and the society - sometime take place in the immaterial virtual public space, more often and in all cases at least also in physical public space of the city or of the built environment respectively: let it be termed as urban public space in a simplified way.

In chapter 1, a brownfield has been introduced as the negative to sustainable development of built environment: the relation provides particular definition of sustainable development of built environment - a negative one - whilst the "classic" Brundtland Report definition [6] turns out to be useless being too general regarding the case: A city development process is sustainable if it brings no decline and abandonment in a city - a locality - an enclave scale. Brownfields - as shown in previous chapter - indicate a deficiency in communication as a general rule. On the other hand, vital public space can be identified with well-functioning communication basis of the city. There is a hypothesis thus: Vital urban public space is the basis of sustainable development of a city. Derived logically from the above facts and definition, the hypothesis appears rather strong.

\section{Reality: the Hypothesis Confronted}

First look as well as a thorough examination of an urban-development plan, which can be regarded as a traditional one in retrospect, indicates focus of the planners' attention: it is an individual functional area and a plot - their functions and uses. Failing repeatedly in the future conditions' and circumstances' forecast, executive urban planning orders to the land owners how to deal with their property - now as well as in distant future. Moreover, in this approach that is a strange relict of modernist era, an urban public space is perceived only as "what remains between the functional areas".

A collection of case studies of sustainable - or non-sustainable development of localities is provided by modern European cities that we live in [2]. They provide examples of achievements of two essential urban planning approaches: one of them is described above, the other focuses on urban public space predominantly. The second used to be applied generally until the fall of modernist era or to the end of so called long 19th century, e.g. till WWI, the first has been ruling urban development since. Recent situation of cities at the east of Germany provides clear comparison of results of the two approaches: As a result of economic imbalance of original and new federative lands, the cities in new lands of reunited Germany face dramatic decrease of inhabitants' number. Nevertheless, the population that remained is not dispersed regularly: as a result of urban public spaces' competition the inhabitants are concentrated along the historical - in 19th century and earlier set streets and squares, whilst housing estates, carefully planned and built after the WWII and providing both higher comfort and wealthier environment, are abandoned. 
During 20th century cities exceeded the borders set by the boom of long 19th century. Industrial and workers' districts started to represent a "gap" between prospering central business districts and new, modern-planned residential neighborhoods at outskirts thus. Soon after, due to its negative externalities, the production started to be perceived as undesirable in "the gap". Together with the industry, other production entities have moved away to new mono-functional localities further at the periphery. Unable to create vital urban public space, the "ghost towns" came up inhabited not more than 8 hours a day, whilst land speculation started in "the gap" [1]. As a result, last inhabitants of "the gap" lost their original workers homes: what remained there was the grid of urban public space - to serve as a base for new, high-end real estate development in a short time. The gentrified localities of the original "gap-ring" are becoming a "good address", saturated with all the benefits of well-functioning, well dimensioned and well equipped urban public space of the 19th century origin - unlike the new, in modern manner at the outskirts planned and built districts: some of them will turn to brownfields rather soon.

Urban public space of today has been inherited by majority: this regards its scope and even more when evaluating the public space's primary significance within a city context. Established in 19th century or - more often - earlier, public space of European cities' centers is both vital and highly appreciated today. As a principle, it is preserved as a valuable patrimony, and if some needs to change it occur, they consist of taking the space from motor transport back to the people most often. The history as well as the functioning of the inherited public spaces of the cities' centers indicates both their sustainability and their significance for the sustainability of the city. Another part of the urban built bequest is the workers' settlements - residential groups and districts dated back to the period before WWII and earlier. Low-cost approach provided a public space in these localities, which is limited both in dimensions and in benefits offered. Nevertheless, whether by means of gentrification or by successive incumbent upgrading, public space of these neighborhoods appears to be adaptable to the needs and expectations of 21 st century inhabitants [3]. At the end, the regenerated and revitalized public space of these "gap localities" proves to be more attractive than the one of the post-WWII residential settlements, planned by methods of recent urban planning that focuses on functional areas dominantly. More successful in competition of the two, the pre-WWII residential groups' public space appears to be more sustainable, indeed.

At last, particular topic regarding the inherited urban public space are the production plants. Squeezing out the original urban or agriculture function, factories gradually occupied vast territories at city outskirts: area of the enclave often competed with the original territory of the city. Initially, following the original street grid or roads' network, a space has been left free between production buildings. However, public was excluded from use of the space, the "streets" did not bear adequate urban functions as a rule. Over time, the development of production and related technology often erased the outdoor spaces: they were absorbed by the adjoining halls, which have grown to unprecedented proportions. Consequently, regeneration procedure principles can be induced: in order to re-vitalize a brownfield, the public space network and functions are to be restored - and the same has to be undertaken as soon as first symptoms of the production decline appear so as to prevent further deterioration and decay of the locality. Nevertheless, the opportunity is ignored most often so far...

\section{Urban Public Space}

Even today, extending their variety and filling them with new purposes, functions and ways of use, urban public space reflects traditional forms of squares, streets, promenades, parks, ... New and unexampled are the forms of virtual public space - the communication media, the Internet and social networks. Nevertheless, neither significance, nor richness of forms nor physical development of urban public space is oppressed or restricted by the "immaterial competition". On the contrary - new types of parks, equipped with playground furnishings and new "urban" sports' facilities emerge in cities and public spaces are equipped with urban furniture that creates unparalleled conditions for 
relax and social activities recently. Urban public space opens and integrates previously separate functions - as an example, boundaries between areas for pedestrians and mechanical transport disappear. It is adapted to the needs of different types of users: for instance, trails with a surface adapted for convenient movement of cyclists and skaters are created within promenade areas. Traditional forms of urban public space are exposed to competition - and successfully react by a renaissance of alleys and urban greenery in general. Public space is expanding - into the interior of adjoining houses of public institutions, to private buildings and to their lands. Public institutions complement their essential roles and purposes by social and community functions: new types of interior public spaces are created to accommodate them, for example, in schools, in galleries and in offices. Social recreation areas occupy the territories, originally dedicated to technical facilities river embankments in cities are an example. There is no doubt that urban public space remains a fundamental part of built environment and a "showcase" of a city: its significance, scope and benefits provided are increasing, and even more is expected spontaneously.

Three core functions of urban public space result from its role of a platform for various forms of physical, social-cultural and social communication. First, the urban public space is a place of consumption of the benefits of the city - material perquisites, social-cultural and social experiences. Consumption is a form of communication: some create and provide benefits and experiences whilst the others adopt and enjoy them, whether it is traditional amenities - shops, services, schools, theaters, entertainment venues, galleries, sports facilities - or informal social and cultural activities happenings, street theater and street art, community nooks and playgrounds, "flea" and farmers' markets - or traditional promenade in festive days. Security that even today remains a benefit, which provides a city, a place of identity, social contacts or shared cultural experiences of everyday life are objects of consumption, too. Second, urban public space mediates - physically and mentally conveys the consumption of benefits, perks and experiences described firstly. Social-cultural activities and urban benefits that take place both in adjoining buildings and in the open public space itself are made accessible thus. Naturally, the civil engineering works both of the public space and the adjoining ones - their architectures and experiences, provided "by themselves" - are accessed and interpreted by the urban public space, too. Interpretation of construction works, or rather of architecture is a specific and extremely important part of mediative role of public space: the paper shall come back to it later when explaining the relation between construction work, architecture and public space. However, production, delivery, acceptance and exchange of benefits, perquisites and experiences request to be provisioned, too: supply of energy, water, people, material, ... is finally the third function of urban public space. Concisely, it is possible to speak about benefits - mediation and provisioning regarding the functions of urban public space.

The geometry of urban public space follows its functions: defined by the geometry of its structure, density and shaping of the grid - and by the profiles of particular places of the structure, the urban public space shall follow the fluxes and the focal points of social-cultural and material values' communication within a city ceaselessly. Within a network of urban public space, other profile appertains to a quiet residential street or to a neighborhood nook, another to a busy boulevard or to a central square - and again another to the park adjacent. Regarding at least some of its functions, an urban public space profile includes not only the street or square, but also adjoining areas of reserved land - typically a private garden for example - and also interior spaces, where social-cultural activities, urban and "ordinary" services and retail take place. Although more or less reserved and limited in an access, all the above mentioned premises work as a public space regarding both mediation, benefits' and provisioning function of an urban public space.

The structure of urban communication within a large and complex city - not to mention within built environment as a whole - is a multi-level one naturally. This refers to the urban public space structure consequently: its grid becomes 3-dimensional both conceptually and in reality. A city starts to be perceived as a metropolis - and its structure regarded as metropolitan thus. Spontaneously and instantly, the point of view begins to apply to small towns, too. 
Construction work, architecture and public space: a particular contextual basis belongs to each of the urban public space functions. Regarding the design process and its bottom-lines, an architecture "by itself" is the bearer of the benefits' function whilst the mediation function is bound to an urban space platform, to a wider context or "surroundings". The provisioning function, finally, bears the construction structure of physical public space primarily. Particular architectures shape the physical public space of built environment: this encompasses the architecture of buildings and related structures as well as the architectural equipment of public space represented by its surfaces, shapes, the so-called "small architecture" or "street furniture". Within the public space framework, or rather within the urban communication context, particular architecture appears to be a physical spatial structure created by man and persisting at a particular place, resonating with the socialcultural values of the environment: once positioned in public space - both physical and virtual - a built structure or a construction work becomes architecture. The resonance means mutual communication - providing and adopting of social-cultural values between the architecture on the one hand and the society and individuals present in the public space on the other. Intensity "amplitude", or "+/- sign" of the resonance gives then, whether it is a marginal architecture, iconic object of art - or entity, producing mostly negative reactions. In all the cases, however, there are social-cultural values communicated. Architecture is both subject and object of the communication. Intensity and quality of the resonation interferes with the sustainability of the architecture. The mediating role of public space shall be revisited: Created by the surrounding architectures, the public space "creates" the architectures. As soon as exposed to the public space, even a construction work, originally conceived as a purely engineering one without conscious social-cultural ambitions, resonates social-cultural values spontaneously. And on the contrary: outside the public space architecture does not exist, there is no architecture if there is not enough social-cultural values communicated.

\section{Conclusions}

The focus on urban public space and communication base of the city reminds of both the fundamental responsibility and competencies of architecture and urban planning referring to sustainable development of built environment as well as sustainable life in general. It is appropriate to point them out in a situation when energy consumption of buildings, declining in most of industrialized countries, is regarded as a major contribution to sustainable development of mankind. The primary liaison between energy efficiency of the building as a cause and permanent or at least long-term sustainability of it as a consequence has not been established. Regarding both sustainable development of built environment and sustainable life on Earth, the role of architecture persistent in vital public space proves to be essential. Physical structure of a building has only a lifespan at its disposal that is limited inherently: potential improvements of energy efficiency or renewal of material substance of buildings derive only from the eligibility and prospects of the architecture.

\section{References}

[1] E. Clark, The Rent Gap Re-examined, Urban Studies, Vol. 32, No. 9, 1995.

[2] J. Jacobs, The Economy of Cities, New York: Random House, 1970.

[3] N. Smith, Toward a Theory of Gentrification, APA Journal, 1979.

[4] M. McLuhan, Understanding Media. The Extensions of Man: McGraw-Hill, 1964.

[5] S. Zukin, Naked City: The Death and Life of Authentic Urban Place: Routledge, 2009.

[6] World Commission on Environment and Development: Our Common Future, Report of the WCED, Annex to General Assembly Document A/42/427, Development and International Cooperation: Environment, August 2, 1987, retrieved 2007. 